\title{
Protective role of ABCG2 against oxidative stress in colorectal cancer and its potential underlying mechanism
}

\author{
SHUANG NIE ${ }^{1 *}$, YAQING HUANG ${ }^{2 *}$, MENGYUE SHI $^{*}$, XUETIAN QIAN $^{1}$, HONGZHEN LI $^{1}$, \\ CHUNYAN PENG ${ }^{1}$, BO KONG ${ }^{1}$, XIAOPING ZOU ${ }^{1}$ and SHANSHAN SHEN ${ }^{1}$ \\ ${ }^{1}$ Department of Gastroenterology, Drum Tower Hospital, Medical School of Nanjing University, \\ Nanjing, Jiangsu 210008; ${ }^{2}$ Department of Rheumatism and Immunology, \\ Children's Hospital of Soochow University, Suzhou, Jiangsu 215000, P.R. China
}

Received March 14, 2018; Accepted July 12, 2018

DOI: $10.3892 /$ or.2018.6594

\begin{abstract}
Colorectal cancer (CRC), one of the most common cancer types worldwide, is associated with a high mortality rate, and oxidative stress and inflammation play a vital role in this malignancy. A previous study by our group indicated that ATP binding cassette subfamily $\mathrm{G}$ member 2 (ABCG2) was capable of protecting cells from reactive oxygen species (ROS)-mediated cell damage and death. In the present study, the role of ABCG2 in CRC was investigated by using clinical samples and cell lines. The levels of oxidative stress markers and inflammatory factors were increased, while the levels of antioxidants were decreased in CRC tissues or the serum of patients. Notably, high expression of ABCG2 in CRC tissues which may be the feedback of over-oxidative reaction, was associated with a poor prognosis. Further in vitro study indicated that the downregulation of ABCG2 induced ROS generation and inflammatory reactions, and inhibited the production of antioxidants. The nuclear factor (NF) $-\kappa \mathrm{B}$ signaling pathway was activated under oxidative stress induced by $\mathrm{ABCG} 2$ knockdown. In conclusion, the present results indicated that $\mathrm{ABCG} 2$ may relieve oxidative stress and inflammatory response by inhibiting the $\mathrm{NF}-\kappa \mathrm{B}$ signaling pathway in cell models, and may thus play a potential protective role in CRC. This information may provide novel theoretical mechanisms and future targets for CRC therapy.
\end{abstract}

\section{Introduction}

Colorectal cancer (CRC) is one of the most common cancer types worldwide with the highest incidence rate in western

Correspondence to: Dr Shanshan Shen, Department of Gastroenterology, Drum Tower Hospital, Medical School of Nanjing University, 321 Zhongshan Road, Gulou, Nanjing, Jiangsu 210008, P.R. China

E-mail: shanshanshen33@hotmail.com

*Contributed equally

Key words: colorectal cancer, ATP binding cassette subfamily G member 2, oxidative stress, inflammation, nuclear factor $\kappa \mathrm{B}$ countries (1). The prognosis of CRC patients is poor, due to frequent metastasis and recurrence. Therefore, it is important to further study the pathogenesis of CRC and explore novel effective treatments. Risk factors, including smoking, alcohol consumption, environmental factors, diet and obesity lead to oxidative stress in the colorectal environment, causing an overproduction of reactive oxygen species (ROS) (2). ROS are in certain ways detrimental to various cellular macromolecules, interfering with cellular function (3). DNA damage may occur, causing chromosomal instability and aneuploidy (4). This resulting oxidative damage is the first step involved in mutagenesis and carcinogenesis $(5,6)$. Furthermore, excessive and uncontrollable production of ROS for an extended period of time leads to persistent inflammation (7). It is widely known that inflammation in the colonic environment is a vital risk factor for CRC. Patients with inflammatory bowel disease, including ulcerative colitis or Crohn's disease, have a 6-fold increased risk of developing colitis-associated cancer compared with the general population (8). Overall, the association between oxidative stress, inflammation and CRC has been broadly evidenced.

ATP binding cassette (ABC) subfamily $G$ member 2 (ABCG2), also known as breast cancer resistant protein, is an $\mathrm{ABC}$ transporter and is abundantly expressed in the apical membrane of the normal colonic epithelium (9), playing an important role in maintaining normal physiological function by protecting normal cells via efflux of a variety of carcinogens, drugs or toxic substances $(10,11)$. ABCG2 has been demonstrated to be associated with chemoresistance in CRC (12). However, the association between ABCG2 and the onset or development of $\mathrm{CRC}$ remains to be fully elucidated and the expression pattern of $\mathrm{ABCG} 2$ in $\mathrm{CRC}$ also remains controversial. Gupta et al (13) reported that ABCG2 mRNA expression was present in normal colorectal tissues and was 6-fold decreased in cancer tissues. Furthermore, Liu et al (14) indicated that the expression rate of ABCG2 in carcinomatous tissues was higher compared with that in tissues from the non-carcinomatous margin. It may therefore be suggested that ABCG2 was associated with colorectal carcinogenesis, while the mechanism and its influence on patient prognosis remains elusive. 
A previous study by our group indicated that ABCG2 has a protective role against oxidative stress by decreasing the level of cellular heme and inhibiting ROS signaling-mediated nuclear factor (NF)- $\kappa \mathrm{B}$ activation, leading to a decreased expression of inflammatory genes (15). Due to the fact that oxidative stress and inflammation have an effect on the development of $\mathrm{CRC}$, and $\mathrm{ABCG} 2$ has a protective role during oxidative stress and is aberrantly expressed in cancer tissues, it may be hypothesized that the upregulation of ABCG2 in CRC tissues is an adaptive response to relieve oxidative stress and protect colonic epithelial cells against ROS-induced damage and inflammation by inhibiting the $\mathrm{NF}-\kappa \mathrm{B}$ signaling pathway.

In the present study, immunohistochemical analysis of CRC specimens was performed and the association of ABCG2 with the clinicopathological factors of patients was analyzed to evaluate the significance of ABCG2. The role of ABCG2 in the mechanism of colorectal carcinogenesis was also explored by examining the association between ABCG2, ROS generation, inflammatory gene expression and the probable signaling pathways.

\section{Materials and methods}

Patients. Eighty-three CRC, 24 colorectal adenoma patients and 24 normal colorectal tissues from the same adenoma patients with complete clinical information, who were treated at Nanjing Drum Tower Hospital (Nanjing, China) between January 2007 and August 2013 were collected. The experimental study was approved by the Ethics Committee of Nanjing Drum Tower Hospital, and the informed consent forms were obtained when the patients were accepted for the study by the hospital.

ROS assay. For the ROS assay, negative control and ABCG2knockdown HT-29 cells were treated with 0,1 and $2 \mathrm{mM}$ $\mathrm{H}_{2} \mathrm{O}_{2}$ for $4 \mathrm{~h}$, following which cells were incubated with $5 \mu \mathrm{M}$ 2',7'-dichlorofluoresceindiacetate (DCFDA; Sigma-Aldrich; Merck KGaA, Darmstadt, Germany) for $25 \mathrm{~min}$. To remove excess DCFDA, the cells were washed twice with PBS. Labeled cells were then trypsinized and re-suspended in PBS. The mean fluorescence intensity was analyzed by flow cytometry to determine the intracellular ROS concentration.

To detect ROS levels in tissues, fresh normal human colorectal mucosal tissues, colorectal adenoma or tumor tissues from patients were collected and lysed, and the supernatant was collected to detect ROS levels using a ROS detection kit (cat. no. E004; Nanjing Jiancheng Bioengineering Institute, Nanjing, China) according to the manufacturer's protocol.

Detection of oxidative stress-associated markers and inflammatory factors. Glutathione (GSH) detection. Equal numbers of negative control and ABCG2-knockdown HT-29 cells were seeded in 6-well plates and cultured overnight. Cells were treated with 0 or $1 \mathrm{mM} \mathrm{H}_{2} \mathrm{O}_{2}$ for $4 \mathrm{~h}$ and then collected to detect GSH levels in the cell lysate using a Glutathione Colorimetric Assay kit (cat. no. K261-100; BioVision, Milpitas, CA, USA) according to the manufacturer's protocol.

IL-8 detection in cell culture medium. Equal numbers of negative control and ABCG2-knockdown HT-29 cells were seeded in 6-well plates and grown overnight. Cells were treated with 0,1 or $2 \mathrm{mM} \mathrm{H}_{2} \mathrm{O}_{2}$ for $4 \mathrm{~h}$ and the culture medium was collected to detect IL-8 using a Human IL-8 Coated ELISA kit (cat. no. BMS204-3; Invitrogen; Thermo Fisher Scientific, Inc., Waltham, MA, USA) according to the manufacturer's protocols.

Serum superoxide dismutase (SOD), malondialdehyder (MDA) and GSH detection. Venous blood $(5 \mathrm{ml})$ was drawn from the antecubital vein of patients using a sterile disposable syringe and transferred to an EDTA-containing vial. The blood was centrifuged for $10 \mathrm{~min}$ at $4^{\circ} \mathrm{C}$ at $1,500 \mathrm{x}$ g and plasma was separated. Serum SOD, MDA and GSH levels were detected using a SOD Activity Colorimetric sssay kit (cat. no. K335100; BioVision), a Lipid Peroxidation (MDA) Colorimetric/ fluorometric assay kit (cat. no. K739-100; Biovison) and a Glutathione Colorimetric Assay kit (cat. no. K261-100; BioVision), respectively, according to the manufacturer's protocols.

Tumor necrosis factor (TNF)- $\alpha$ detection in tissues. Fresh human normal colorectal mucosal tissues, colorectal adenoma or tumor tissues from patients were collected and lysed, and the supernatant was collected to detect TNF- $\alpha$ levels using a Human TNF- $\alpha$ Platinum ELISA kit (cat. no. BMS223/4; Invitrogen; Thermo Fisher Scientific, Inc.) according to the manufacturer's protocol.

Immunohistochemistry. For histological analysis, normal human colorectal mucosal tissues, colorectal adenoma or tumor tissues from patients were fixed in $10 \%$ buffered formalin (Sigma-Aldrich) and embedded in paraffin. Paraffin sections were then processed for either hematoxylin and eosin (H\&E) staining or immunohistochemistry. Antibodies used for immunostaining are listed in Table I. The proportion of stained areas was evaluated as follows: $0,<5 \% ; 1, \geq 5 \%$ and $<25 \% ; 2, \geq 25 \%$ and $<50 \% ; 3, \geq 50 \%$ and $<75 \% ; 4, \geq 75 \%$. The intensity of staining was scored as follows: 0 , yellow; 1 , brown; 2, dark brown and 3 for the absence of staining. The final scores were obtained by multiplying the area and intensity scores, producing a range of $0-12$. For ABCG2, samples with scores of at least 2 were considered positive. For NF- $\kappa B$, samples scoring 4 points and above were considered positive. The stained slides were independently evaluated by two experienced pathologists.

RNA extraction and reverse transcription-quantitative polymerase chain reaction $(R T-q P C R)$. Total RNA was isolated using TRIzol reagent (Takara Bio Inc., Otsu, Japan) according to the manufacturer's instructions. RT reactions were performed with $1 \mu \mathrm{g}$ total RNA using the PrimeScript ${ }^{\mathrm{TM}}$ RT Master Mix (Takara Bio Inc.). qPCR was performed in a total reaction volume of $20 \mu \mathrm{l}$ in 96-well reaction plates using SYBR ${ }^{\circledR}$ Advantage ${ }^{\circledR}$ qPCR Premix (Takara Bio, Inc.) according to the manufacturer's protocols. The sequences of the primers used are listed in Table II. qPCR was performed at $95^{\circ} \mathrm{C}$ for $30 \mathrm{sec}$, followed by 40 cycles at $95^{\circ} \mathrm{C}$ for $5 \mathrm{sec}$ and $60^{\circ} \mathrm{C}$ for $30 \mathrm{sec}$ using LightCycler ${ }^{\circledR} 96$ system (Roche Diagnostics, Basel, Switzerland). Reactions were run in triplicate in three independent experiments. The $2^{-\Delta \Delta \mathrm{Cq}}$ method (16) 
Table I. Antibodies used in the present study.

\begin{tabular}{|c|c|c|}
\hline Antibody & Assay & Supplier/catalogue no. \\
\hline Anti-BCRP/ABCG2 & WB, IHC & Abcam; ab24115 \\
\hline Anti-NF- $\kappa$ B p65 & $\mathrm{IHC}$ & Abcam; ab16502 \\
\hline Phospho-I $\kappa \mathrm{B} \alpha$ (Ser32) (14D4) rabbit mAb & WB & Cell Signaling Technology; \#2859 \\
\hline$\beta$-actin & WB & Bioworld; AP0060 \\
\hline HRP-linked anti-mouse IgG & WB & Cell Signaling Technology; \#7076 \\
\hline HRP-linked anti-rabbit IgG & WB & Cell Signaling Technology; \#7074 \\
\hline
\end{tabular}

WB, western blotting; IHC, immunistochemistry; Abcam, Cambridge, UK; Cell Signaling Technology, Inc., Danvers, MA, USA; Bioworld Technology, Inc., St. Louis Park, MN, USA.

was used to determine the relative levels of mRNA expression in experimental samples and controls. Specific primers were listed in Table II. $\beta$-actin was amplified as an internal control.

Western blot analysis. Cell and tissue lysates were obtained as previously described (17). Protein concentrations were determined using the bicinchoninic acid assay (Beyotime Institute of Biotechnology, Haimen, China). Protein lysates (30-60 $\mu \mathrm{g} /$ lane) were separated by $6-12 \%$ SDS-PAGE and transferred to polyvinylidene difluoride membranes (EMD Millipore, Billerica, MA, USA). Tris-buffered saline containing Tween-20 with 5\% non-fat milk or bovine serum albumin (BioFroxx GmbH, Einhausen, Germany) was used to block non-specific binding for $2 \mathrm{~h}$ at room temperature. The membranes were then incubated with primary antibodies (1:50 dilution) according to the manufacturer's protocols overnight at $4{ }^{\circ} \mathrm{C}$, followed by appropriate horseradish peroxidase-conjugated secondary antibodies for $1 \mathrm{~h}$ at room temperature (1:5,000 dilution). Signals generated by enhanced chemiluminescence (EMD Millipore) were recorded with a CCD camera (Tanon, Shanghai). Primary and secondary antibodies are listed in Table I.

Cell culture. The human CRC cell lines HCT-8, HCT-116, HT-29, Colo-205, SW480, SW620, Caco-2 and SW116 were purchased from the Cell Bank of the Chinese Academy of Sciences (Shanghai, China), and LS-180 (ATCC CL-187TM) (18) was purchased from ATCC. All cell lines were cultured in RPMI-1640 medium (Gibco; Thermo Fisher Scientific, Inc.) supplemented with $10 \%$ fetal bovine serum (FBS; Biological Industries, Cromwell, CT, USA) in a humidified atmosphere with $5 \% \mathrm{CO} 2$ at $37^{\circ} \mathrm{C}$. The HT-29 cell line with high ABCG2 expression was selected for further study.

Lentiviral transfection. The ABCG2 small hairpin (sh)RNA lentiviral vector was constructed by GeneChem Co. Ltd (Shanghai, China) from GV298 vector (U6-MCS-UbiquitinCherry-IRES-puromycin). The targeting sequence of ABCG2 shRNA was 5'-CTCGATATTCCATCTTCAA-3'. An empty vector was used as a negative control. To generate the HT-29 cell line with stable ABCG2 knockdown, cells were seeded in a 6 -well plate at a density of $1 \times 10^{5}$ cells/well and following 1 day of culture, $1 \times 10^{6}$ units of lentivirus were added to the cell culture medium supplemented with $5 \mu \mathrm{g} / \mathrm{ml}$ Polybrene to initiate transfection. Following $12 \mathrm{~h}$ of culture, the medium was replaced with fresh normal cell culture medium. At 3 days post-transfection, $5 \mu \mathrm{g} / \mathrm{ml}$ puromycin was added to the cell culture medium to generate the stable ABCG2-knockdown HT-29 cell line.

Statistical analysis. Data were analyzed using GraphPad Prism v6.0 (GraphPad Inc., La Jolla, CA, USA). Unless otherwise indicated, all experiments were performed in triplicate, and the results were expressed as the mean and standard deviation where appropriate. Differences among detected marker values (oxidative stress markers, inflammatory factors and antioxidants) in in vitro studies were evaluated using analysis of variance (ANOVA) or Student's t-test. Multiple comparison between the groups was performed using Student-NewmanKeuls (SNK) method. The differences in ABCG2 and NF- $\kappa$ B expression by immunohistochemistry among patients were analyzed by a Chi-squared test for categorical variables. The differences in ABCG2 expression among patients with diffferent clinicopathological characteristics were analyzed by a chi-squared test for categorical variables. Correlations between $\mathrm{ABCG} 2$ and $\mathrm{NF}-\kappa \mathrm{B}$ expression were analyzed by the Spearman's Rank-Order method. Log-rank tests were performed on Kaplan-Meier survival curves to determine any significant associations between ABCG2 expression and patient outcomes. $\mathrm{P}<0.05$ was considered to indicate statistically significant differences.

\section{Results}

Oxidative stress and inflammation in CRC tissues. Previous studies have indicated a close association between oxidative stress, inflammation and CRC. To further identify this association, 83 CRC, 24 colorectal adenomas and 24 normal colorectal mucosa tissues from the same adenoma patients with complete clinical information, treated at Nanjing Drum Tower Hospital (Nanjing, China) between January 2007 and August 2013 were collected. The serum and tissue homogenate supernatants were obtained to detect oxidative stress-associated markers and the expression of inflammatory genes. The results indicated that the ROS levels in the serum and homogenate supernatants were increased from normal tissue to adenoma to cancer $(\mathrm{P}<0.05, \mathrm{P}<0.01$; Fig. $1 \mathrm{~A})$. To determine the redox state of the cells, the antioxidants SOD and GSH and the 
A

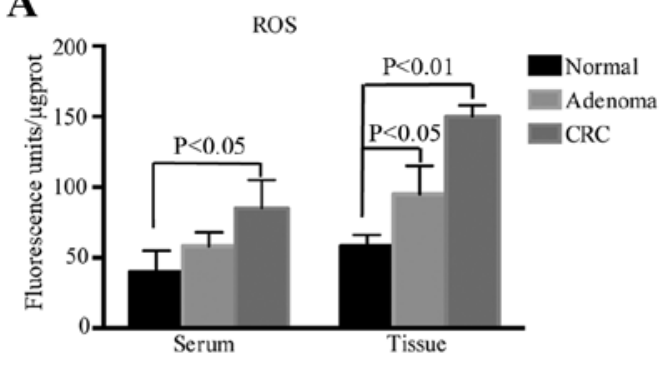

C

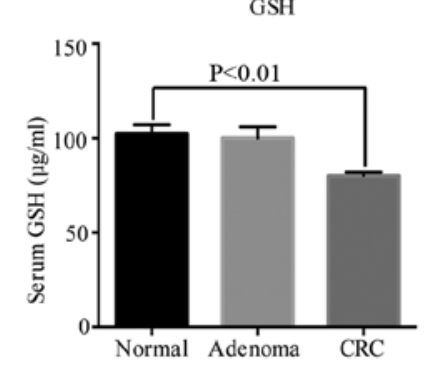

B

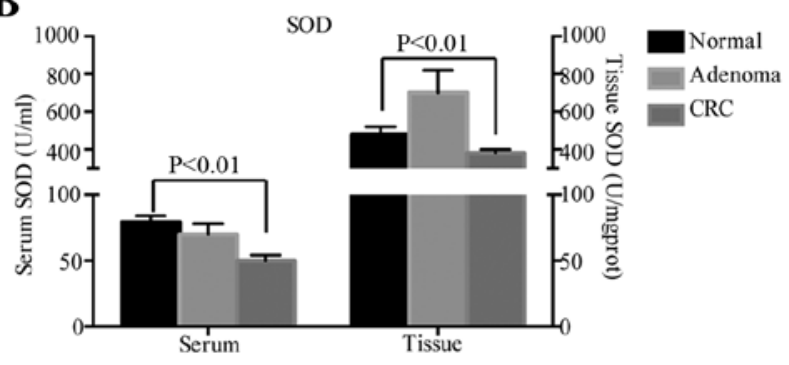

D

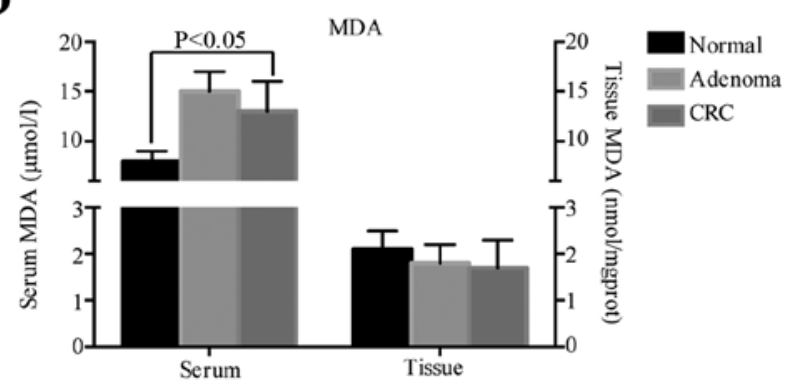

$\mathbf{E}$

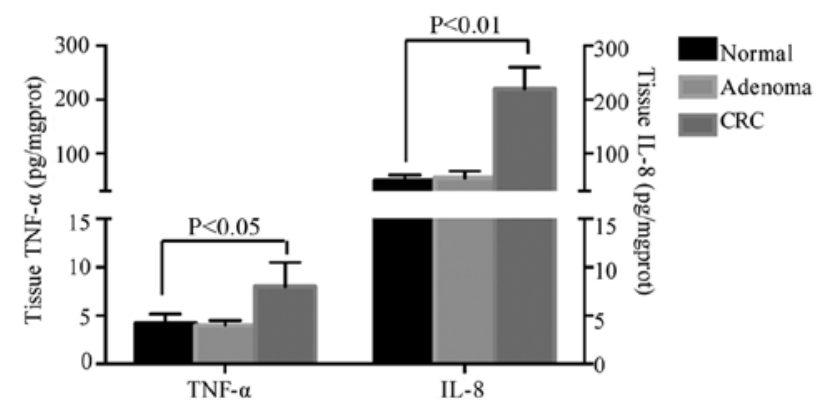

Figure 1. Oxidative stress and inflammation in CRC tissues. (A) Levels of ROS, (B) SOD, (C) GSH, (D) MDA, (E) TNF- $\alpha$ and IL-8. CRC, colorectal cancer; MDA, malondialdehyde; TNF, tumor necrosis factor; IL, interleukin; ROS, reactive oxygen species; SOD, superoxide dismutase; GSH, glutathione

oxidative damage product MDA were detected in the tissues and serum of the patients. In the serum, the levels of SOD in the CRC group were lower than those in the normal groups $(\mathrm{P}<0.01$; Fig. 1B, left) and GSH was significantly decreased in CRC samples compared with that in normal samples $(\mathrm{P}<0.01$; Fig. 1C). In the homogenate supernatants, the results regarding SOD were similar to those obtained in serum (Fig. 1B, right), while GSH was not detected. In terms of oxidative damage products, the serum levels of MDA in the CRC patients were higher than those in the normal group $(\mathrm{P}<0.05$; Fig. 1D, left), while no difference was observed in fresh tissues from the different groups (Fig. 1D, right). These results indicated that oxidative stress prevailed in CRC and that it may play a role in the onset and development of tumors.

Excessive and uncontrollable production of ROS for a long period of time may result in persistent inflammation, which is an important factor in carcinogenesis. In the present study, inflammatory factors were also detected in tissue homogenates from the different groups by ELISA to determine whether any inflammatory reaction was present. The levels of TNF- $\alpha$ in cancer tissues significantly surpassed those in normal tissues $(\mathrm{P}<0.05)$ and IL-8 exhibited a similar trend to that of TNF- $\alpha$
Table II. Sequences of the primers used.

\begin{tabular}{ll}
\hline Primer & \multicolumn{1}{c}{ Sequence } \\
\hline ABCG2 & F: 5'-GTGTTTATGATGGTCTGTTGGTCA-3' \\
& R: 5'-TGCTGCAAAGCCGTAAATCC-3' \\
IL-8 & F: 5'-AGCTGGCCGTGGCTCTCT-3' \\
& R: 5'-TTTAGCACTCCTTGGCAAAACTG-3' \\
MCP-1 & F: 5'-GACCATTGTGGCCAAGGAGAT-3' \\
& R: 5'-TGCTTGTCCAGGTGGTCCAT-3' \\
GRO- $\beta$ & F: 5'-ACTCAAGAATGGGCAGAAAGCTT-3' \\
& R: 5'-TCAGCATCTTTTCGATGATTTTCTTA-3' \\
$\beta$-actin & F: 5'-AGCGAGCATCCCCCAAAGTT-3' \\
& R: 5'-GGGCACGAAGGCTCATCATT-3' \\
\hline
\end{tabular}

F, forward; R, reverse.

$(\mathrm{P}<0.01$; Fig. 1E). These results indicated that inflammatory factors are activated in CRC. 
A

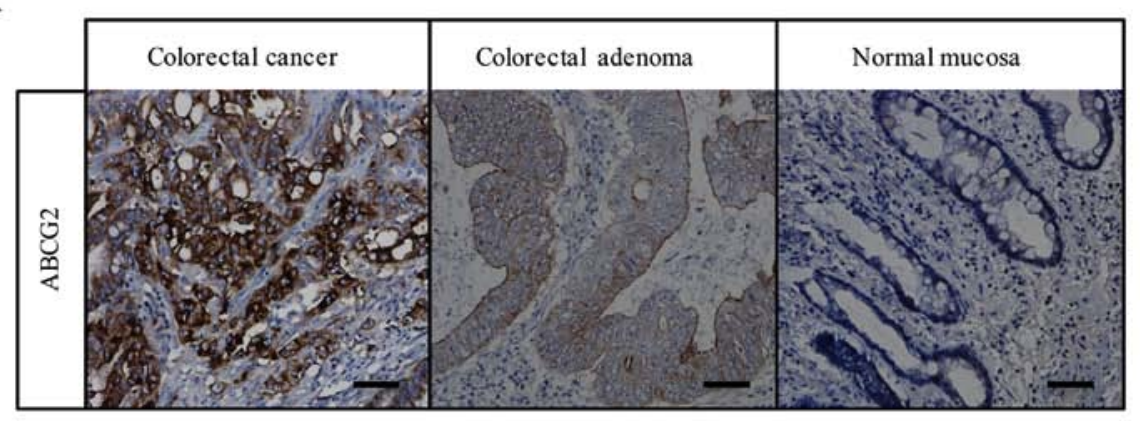

B

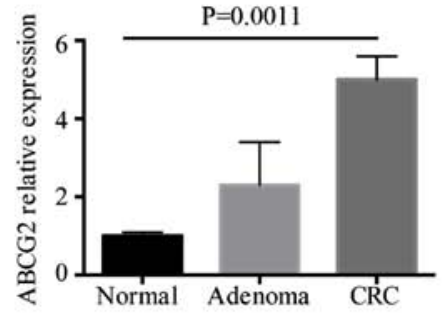

C

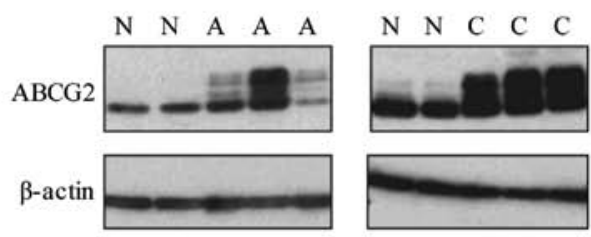

N: normal tissue; A: adenoma; C: colorectal cancer

D

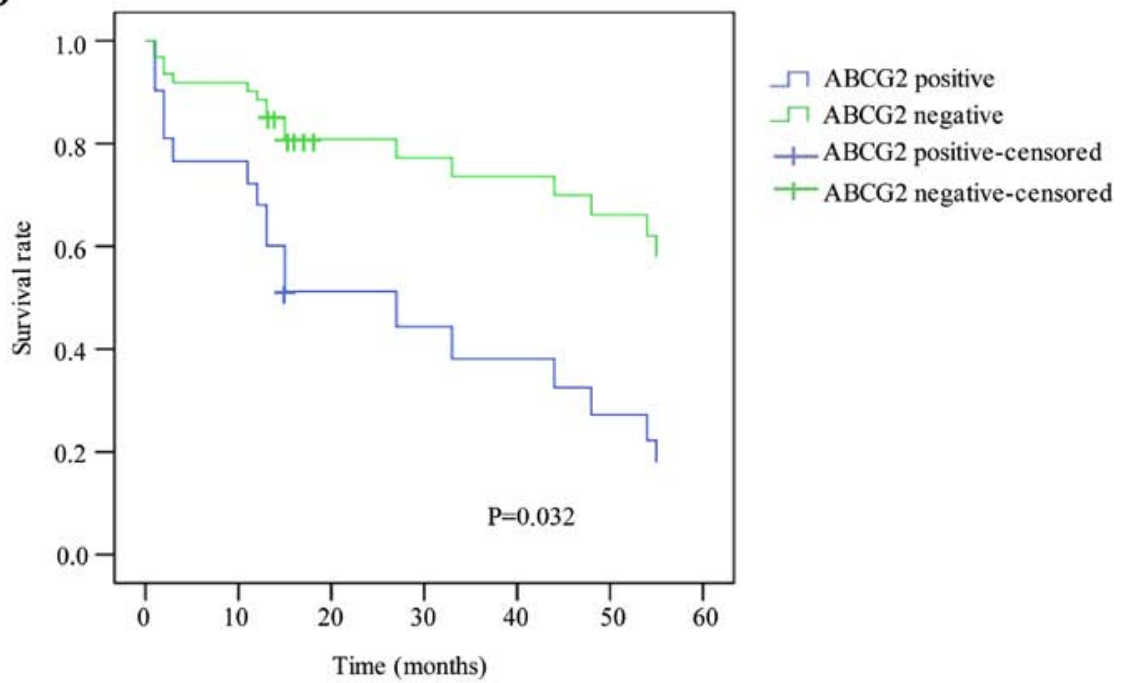

Figure 2. ABCG2 expression decreases during human CRC progression and metastasis. (A) Expression of ABCG2 was determined by immunohistochemistry (scale bar, $100 \mu \mathrm{m}$ ). (B) ABCG2 mRNA expression and (C) ABCG2 protein expression. (D) Survival rates of CRC patients. CRC, colorectal cancer; ABCG2, ATP binding cassette subfamily G member 2.

ABCG2 expression increases during human CRC progression and metastasis. ABCG2 has been reported to be aberrantly expressed in CRC and to play a role in regulating oxidative stress, which may be associated with tumor development (14). To further examine this, ABCG2 expression was assessed in fresh tissues from the different groups in the present study. The mRNA levels of ABCG 2 were detected by RT-qPCR and the protein levels were assessed by western blotting and immunohistochemistry. Immunohistochemical staining indicated that ABCG2 was mainly localized in the membrane and/or cytoplasm of colonic epithelial cells. Staining for ABCG2 was identified in $86.7 \%(72 / 83)$ of CRC tissues, and $54.2 \%(13 / 24)$ of colon adenoma tissues, while $66 \%(16 / 24)$ of normal colon mucosa tissues were negative (Fig. 2A). A significant difference in ABCG2 expression was observed among malignant, pre-malignant and normal tissues $(\mathrm{P}<0.001$; Table III). In fresh
Table III. ABCG2 expression by immunohistochemistry in different groups.

\begin{tabular}{lccccc}
\hline Tissues & $\begin{array}{c}\text { Total } \\
(\mathrm{n})\end{array}$ & $\begin{array}{c}\text { Positive } \\
(\mathrm{n})\end{array}$ & $\begin{array}{c}\text { Negative } \\
(\mathrm{n})\end{array}$ & $\begin{array}{c}\chi^{2} \\
\text { value }\end{array}$ & P-value \\
\hline CRC & 83 & 72 & 11 & 29.832 & $<0.001$ \\
Adenoma & 24 & 13 & 11 & & \\
Normal & 24 & 8 & 16 & & \\
\hline
\end{tabular}

tissues, RT-qPCR and western blotting results indicated that the expression of ABCG2 in CRC and adenoma tissues at the mRNA $(\mathrm{P}=0.0011)$ and protein level was higher than that in normal tissues (Fig. 2B and C). 
A

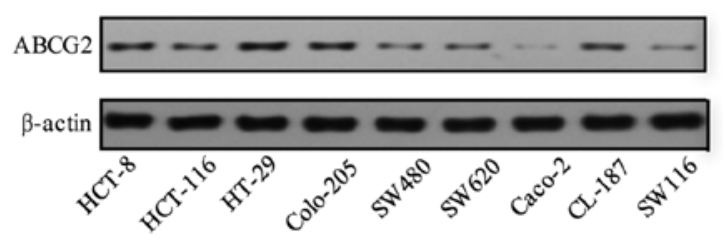

D

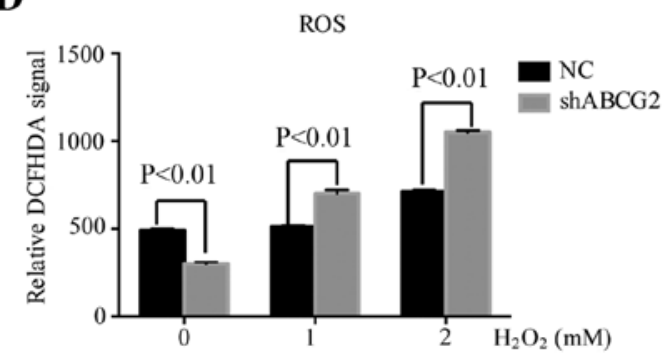

B

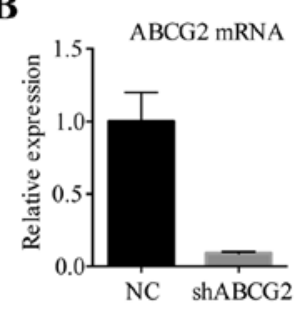

C

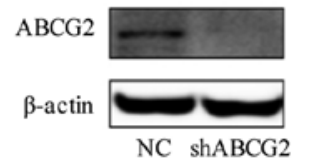

$\mathbf{E}$

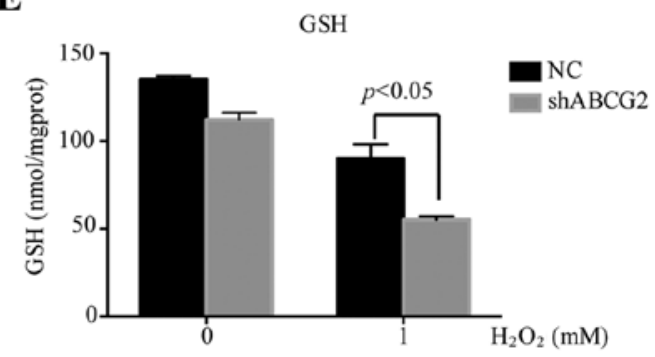

Figure 3. Downregulation of ABCG2 suppresses the antioxidant capacity of HT-29 cells. (A) ABCG2 protein expression in cell lines, (B) ABCG2 mRNA expression, (C) ABCG2 protein expression, (D) ROS levels and (E) GSH activity. ABCG2, ATP binding cassette subfamily G member 2; ROS, reactive oxygen species; GSH, glutathione.

Subsequently, the association between ABCG2 expression in tumor tissues and clinicopathological parameters was analyzed. No correlation was identified between the expression of ABCG2 and age, sex, tumor size, depth of infiltration and tumor grade. However, ABCG2 expression levels in tumor tissues were significantly associated with tumor differentiation and lymph node metastasis. Of the 83 CRC samples, 21 had low differentiation according to the histology, among which 85.7\% (18/21) had high expression of ABCG2, which was significantly higher than that in CRC samples with moderate or high differentiation [50.0\% (31/62), $\mathrm{P}=0.005]$. Among the 35 cancer samples with lymph node metastasis, $88.6 \%$ (31/35) were positive for ABCG2, and in the 48 samples without metastasis, the rate of positivity for ABCG2 was significantly lower [66.7\% (32/48), $\mathrm{P}=0.005$; Table IV). To investigate the prognostic value of ABCG2 expression, 49 cancer patients whose follow-up data were available were enrolled for analysis. Patients were classified into ABCG2-positive and ABCG2-negative groups according to the assessment criteria listed in Materials and methods, and the 5-year survival rates were 28.6 and $71.4 \%$, respectively ( $\mathrm{P}=0.032$; Fig. 2D). Notably, these results indicated that overexpression of ABCG2 which may be the feedback of over-oxidative reaction, was associated with a worse prognosis of CRC, though we suppose ABCG2 could play a protective role in cancer.

Downregulation of ABCG2 suppresses the antioxidant capacity of HT-29 cells. In order to explore the potential mechanism of $A B C G 2$ in regulating the degree of malignancy of CRC, ABCG2 expression was examined in 9 widely used human CRC cell lines (HCT-8, HCT-116, HT-29, Colo-205, SW480, SW620, Caco-2, CL-187 and SW116). The HT-29 cell line with the highest expression levels of ABCG2 was selected for in vitro study (Fig. 3A). shRNA-mediated knockdown resulted in decreased ABCG2 expression at the mRNA and protein levels (Fig. 3B and C). The transfection efficiency of
Table IV. Relationship of ABCG2 expression and clinicopathological characteristics in colorectal cancer.

\begin{tabular}{|c|c|c|c|c|}
\hline \multirow[b]{2}{*}{ Variable } & \multirow{2}{*}{$\begin{array}{c}\text { No. of } \\
\text { cases }\end{array}$} & \multicolumn{2}{|c|}{ ABCG2 staining } & \multirow[b]{2}{*}{ P-value } \\
\hline & & Negative & Positive & \\
\hline \multicolumn{5}{|l|}{ Sex } \\
\hline Male & 40 & 6 & 34 & \multirow[t]{2}{*}{0.751} \\
\hline Female & 43 & 5 & 38 & \\
\hline \multicolumn{5}{|l|}{ Age (years) } \\
\hline$\leq 60$ & 36 & 6 & 30 & \multirow[t]{2}{*}{0.52} \\
\hline$>60$ & 47 & 5 & 42 & \\
\hline \multicolumn{5}{|l|}{ Tumor location } \\
\hline Colon & 45 & 6 & 39 & \multirow[t]{2}{*}{0.981} \\
\hline Rectum & 38 & 5 & 33 & \\
\hline \multicolumn{5}{|l|}{ Differentiation } \\
\hline MD-HD & 62 & 31 & 31 & \multirow[t]{2}{*}{0.005} \\
\hline $\mathrm{LD}$ & 21 & 3 & 18 & \\
\hline \multicolumn{5}{|l|}{ Tumor size $(\mathrm{cm})$} \\
\hline$\leq 4$ & 42 & 6 & 36 & \multirow[t]{2}{*}{0.779} \\
\hline$>4$ & 41 & 5 & 36 & \\
\hline \multicolumn{5}{|l|}{ Depth of invasion } \\
\hline Not serous & 25 & 2 & 23 & \multirow[t]{2}{*}{0.491} \\
\hline Serous and above & 58 & 9 & 49 & \\
\hline \multicolumn{5}{|l|}{ Lymphatic invasion } \\
\hline No & 48 & 16 & 32 & \multirow[t]{2}{*}{0.005} \\
\hline Yes & 35 & 4 & 31 & \\
\hline \multicolumn{5}{|l|}{ Distant metastasis } \\
\hline No & 71 & 8 & 63 & \multirow[t]{2}{*}{0.194} \\
\hline Yes & 12 & 3 & 9 & \\
\hline \multicolumn{5}{|l|}{ TNM stage } \\
\hline $\mathrm{I} / \mathrm{II}$ & 43 & 5 & 38 & \multirow[t]{2}{*}{0.751} \\
\hline III/IV & 40 & 6 & 34 & \\
\hline
\end{tabular}


A

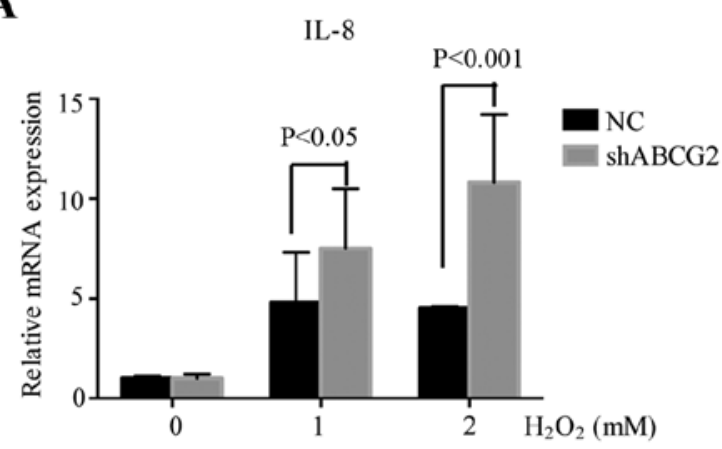

C

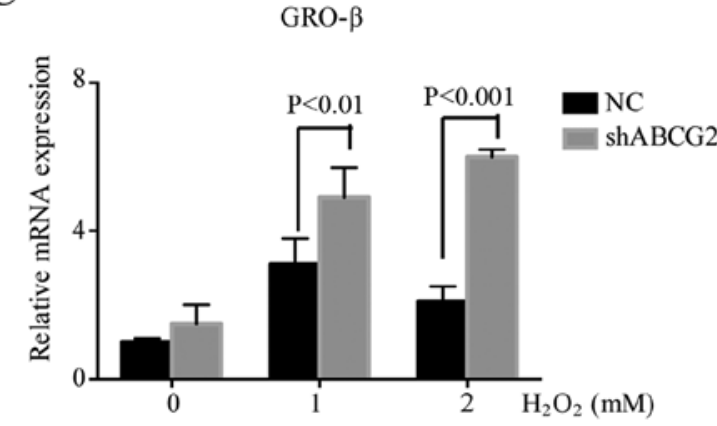

B

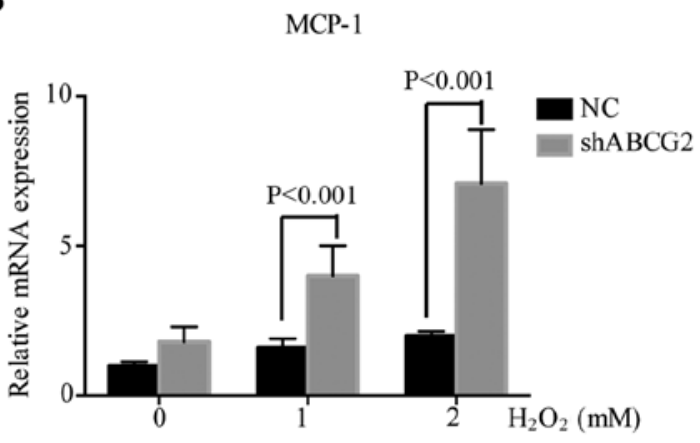

D

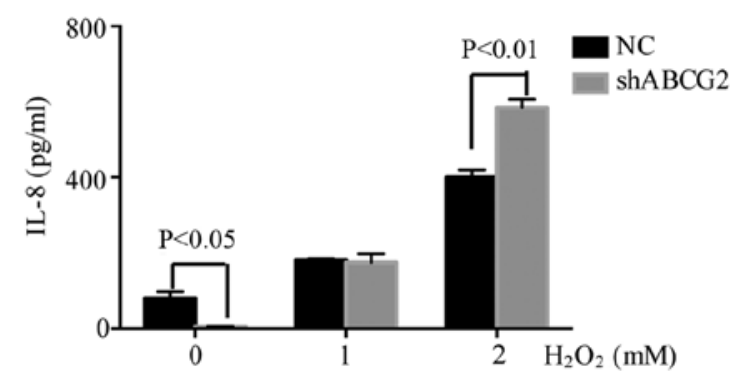

Figure 4. Downregulation of ABCG2 increases the inflammatory reaction in HT-29 cells. Expression of (A) IL-8, (B) MCP-1, (C) GRO- $\beta$ and (D) IL-8 was determined. ABCG2, ATP binding cassette subfamily G member 2; IL, interleukin; MCP, monocyte chemoattractant protein; GRO, growth-related oncogene.

the lentivirus was almost $100 \%$ and the gene silencing efficiency reached $90 \%$ compared with the negative control cells transfected with blank vector.

To assess the antioxidative capacity of the cells, $\mathrm{H}_{2} \mathrm{O}_{2}$ was added to the culture media of HT-29 cells to emulate an oxidative stress environment. ROS activation reflecting redox intensity was assessed via a DCFDA fluorescence assay. At baseline, shABCG2 HT-29 cells produced less ROS than negative control cells. When $\mathrm{H}_{2} \mathrm{O}_{2}$ at different concentrations ( 1 or $2 \mathrm{mM}$ ) was added to the culture media of the cells for $4 \mathrm{~h}$, ROS levels in shABCG2 HT-29 cells were significantly higher than in the negative control cells (Fig. 3D). To further study whether ABCG2 influenced the redox balance by increasing antioxidative products, the levels of GSH were determined in HT-29 cells treated with hydrogen peroxide. At baseline, there was no difference in the levels of GSH between control cells and ABCG2-knockdown HT-29 cells. However, when cells were treated with $\mathrm{H}_{2} \mathrm{O}_{2}(1 \mathrm{mM})$ for $4 \mathrm{~h}$, the levels of $\mathrm{GSH}$ in the shABCG2 HT-29 cells decreased by $40 \%$ compared with those in the negative control cells (Fig. 3E). These results indicated that under oxidative stress, ABCG2 had an important role in redox homeostasis by increasing the expression of antioxidative products.

Downregulation of ABCG2 increases the inflammatory reaction in HT-29 cells. ROS is known to activate the expression of inflammatory genes responsive to oxidative stress. To assess whether ROS induced a cellular inflammatory response in CRC, the expression of IL-8, monocyte chemoattractant protein (MCP-1) and growth-related oncogene (GRO- $\beta$ ) was detected in HT-29 cells treated with various concentrations of $\mathrm{H}_{2} \mathrm{O}_{2}$ (1 or $2 \mathrm{mM}$ ) for $4 \mathrm{~h}$. Furthermore, to explore the association between ABCG 2 and the inflammatory reaction, RNA samples were collected from shABCG2 HT-29 cells and control HT-29 cells treated with $\mathrm{H}_{2} \mathrm{O}_{2}$ (1 or $2 \mathrm{mM}$ ) for $4 \mathrm{~h}$. RT-qPCR analysis indicated that IL-8, MCP-1 and GRO- $\beta$ were induced by ROS, and a further increase was observed in shABCG2 HT-29 cells compared with that in the negative control cells (Fig. 4A-C). ELISA also confirmed that shABCG2 HT-29 cells produced more IL-8 than the control cells (Fig. 4D). These results indicated that oxidative stress promoted inflammation, which was more intense when ABCG2 expression was decreased.

Effects of downregulation of ABCG2 on the $N F-\kappa B$ signaling pathway. The NF- $\mathrm{NB}$ transcription factor is present in the cytosol in a complex with the inhibitory $\mathrm{I} \kappa \mathrm{B}$ protein, remaining inactive. Activation occurs via phosphorylation of $\mathrm{I} \kappa \mathrm{B}$ at Ser32 and Ser36, followed by proteasome-mediated degradation, which results in the release and nuclear translocation of active $\mathrm{NF}-\kappa \mathrm{B}(19)$.

To explore the association between ABCG2 and NF- $\kappa \mathrm{B}$, the expression of $\mathrm{NF}-\kappa \mathrm{B}$ was detected in human $\mathrm{CRC}$, colon adenoma and normal colorectal tissues by immunohistochemistry. NF- $\kappa \mathrm{B}$ was located mainly in the cytoplasm and/or nucleus. In CRC and colon adenoma, 84.3\% (70/83) and $62.5 \%(15 / 24)$ of paraffin-embedded samples were positive for $\mathrm{NF}-\kappa \mathrm{B}$, respectively, while in normal tissues, only $20.8 \%$ were positive (Fig. 5A). Similar to the results of ABCG2 immunostaining obtained in the clinical samples, a significant difference in $\mathrm{NF}-\kappa \mathrm{B}$ expression was identified 
A

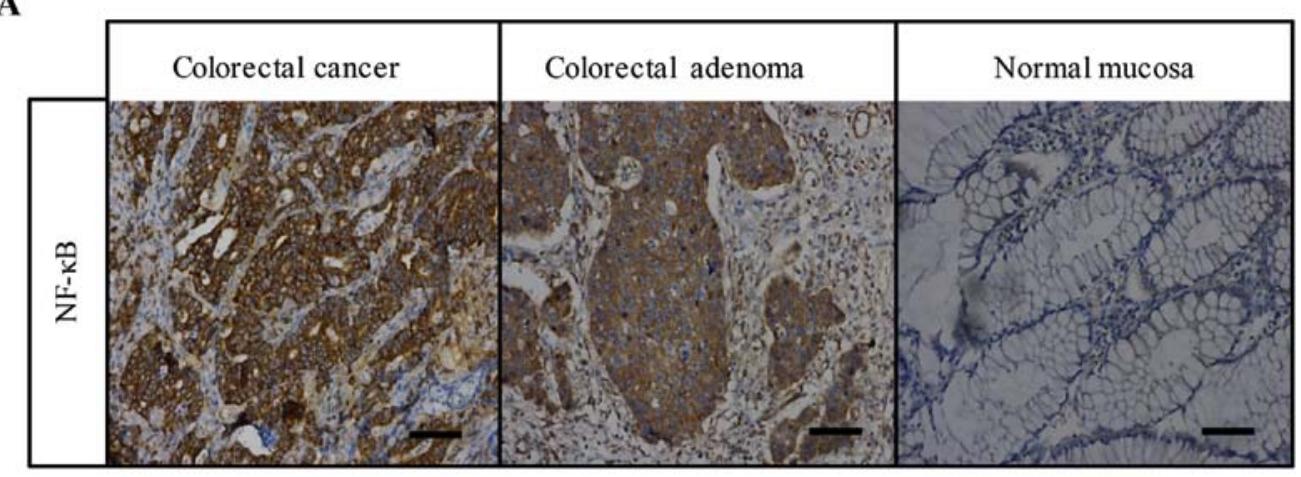

B

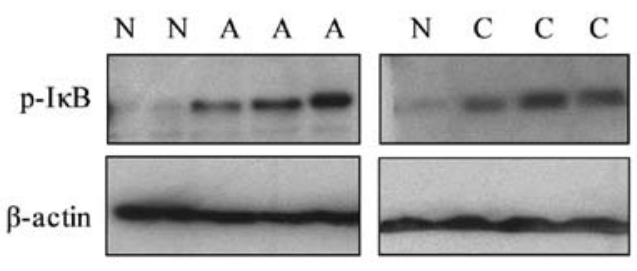

N: normal tissue; A: adenoma; C: colorectal cancer
C

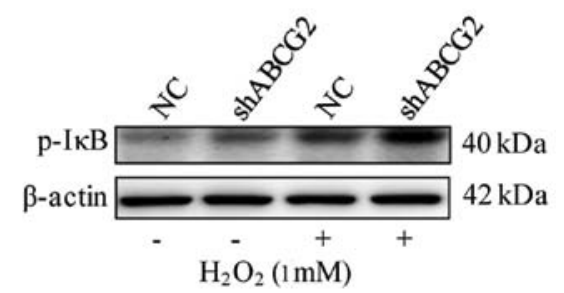

Figure 5. Effects of downregulation of ABCG2 on the NF- $\kappa \mathrm{B}$ signaling pathway. (A) NF- $\kappa \mathrm{B}$ expression by immunohistochemistry (scale bar, $100 \mu \mathrm{m}$ ),

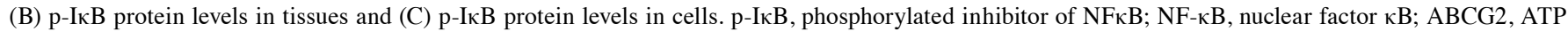
binding cassette subfamily $\mathrm{G}$ member 2 .

Table V. NF- $\kappa \mathrm{B}$ expression by immunohistochemistry in different tissues.

\begin{tabular}{lccccc}
\hline Tissues & $\begin{array}{c}\text { Total } \\
(\mathrm{n})\end{array}$ & $\begin{array}{c}\text { Positive } \\
(\mathrm{n})\end{array}$ & $\begin{array}{c}\text { Negative } \\
(\mathrm{n})\end{array}$ & $\begin{array}{c}\chi^{2} \\
\text { value }\end{array}$ & P-value \\
\hline CRC & 83 & 70 & 13 & 35.442 & $<0.001$ \\
Adenoma & 24 & 15 & 9 & & \\
Normal & 24 & 5 & 19 & & \\
\hline
\end{tabular}

among malignant, pre-malignant and normal tissues $(\mathrm{P}<0.001$; Table V). Furthermore, western blot analysis demonstrated that phosphorylated $\mathrm{I} \kappa \mathrm{B}$ was higher in $\mathrm{CRC}$ and adenoma than in normal tissues (Fig. 5B). In addition, Spearman's rank correlation analysis revealed a positive correlation between ABCG2 and $\mathrm{NF}-\kappa \mathrm{B}$ in CRC tissues ( $\mathrm{r}=0.302, \mathrm{P}=0.026)$.

To further confirm the association between ABCG2 and $\mathrm{NF}-\kappa \mathrm{B}$, the level of phosphorylated $\mathrm{I} \kappa \mathrm{B}$ (Ser32) was examined in $\mathrm{H}_{2} \mathrm{O}_{2}$-treated shABCG2 cells. Exposure to $\mathrm{H}_{2} \mathrm{O}_{2}(1 \mathrm{mM})$ for $4 \mathrm{~h}$ significantly stimulated the phosphorylation of $\mathrm{I} \kappa \mathrm{B}$ in HT-29 cells compared with vehicle treatment. Furthermore, compared with the negative control cells, phosphorylation of IкB was significantly increased in shABCG2 HT-29 cells treated with $\mathrm{H}_{2} \mathrm{O}_{2}$ (at $1 \mathrm{mM}$ ) for $4 \mathrm{~h}$ (Fig. 5C).

\section{Discussion}

The association between oxidative stress and CRC has been intensively studied in the last decade. Oxidative stress, accompanied with overproduction of ROS, is detrimental to various cellular macromolecules, interfering with cellular function (3).
Damage may result in chromosomal instability (4), which is the first step involved in mutagenesis and carcinogenesis (5). CRC originates from the epithelial cells, whose self-renewal and differentiation largely depend on the redox environment in the gut mucosa. These cells divide rapidly and have a high metabolic rate, as a potential factor responsible for the increased oxidation of DNA (20). It was revealed that human colorectal tumor (adenoma and carcinoma) cells had increased levels of ROS and lipid peroxidation product MDA, and decreased levels of the antioxidants SOD and GSH (6). MDA is one of the best known breakdown products of lipid peroxides, acting as signal transducers to modulate several cell functions, including gene expression and cell proliferation (21). Evidence has indicated that MDA could be a marker of oxidative stress which may promote the onset and development of cancer, including CRC (22). Regarding antioxidants, GSH and SOD are essential to protect cells from excessive ROS and to detoxify harmful agents or metabolites (11). The present study revealed increased levels of ROS and MDA, as well as decreased levels of GSH and SOD in the tumor tissues or serum of CRC patients, which indicated that oxidative stress did exist and was associated with CRC.

ABCG2 is abundantly expressed in the apical membrane of the normal colonic epithelium (9), protecting normal cells by effluxing a variety of carcinogens, drugs or toxic substances (11). Aberrant ABCG2 transport function is linked to disease development, including carcinogenesis. The present clinicopathological study indicated that ABCG2 expression was higher in CRC than in non-carcinoma tissues. Furthermore, among CRC patients, high expression of ABCG2 was associated with lower histological differentiation, lymph node metastasis and even shorter 5-year survival. These results indicated that ABCG2 overexpression was 
linked to poorer prognosis of CRC, which was consistent with the studies by Yuan et al (23) and Liu et al (14). However, Gupta et al (13) reported that ABCG2 mRNA levels in CRC tissues exhibited a 6-fold decrease, and they suggested that downregulation of ABCG2 may have a role in the initial stage of cancer by allowing for the accumulation of genotoxins and overproduction of nitric oxide. Several studies have indicated that ABCG2 was induced by hypoxic stress to regulate toxic levels of cellular heme and porphyrin, so as to protect the cell from toxic substrate accumulation (24-26). Thus, it was presumed that ABCG2 expression may vary between different stages of carcinogenesis. In the early stage, ABCG2 may be downregulated to sensitize cells to carcinogens. However, in more advanced stages of CRC, overexpression of ABCG2, as the feedback of ROS or other oxidant overproduction, exerts a protective effect on cancer cells. The possible mechanism in which ABCG2 has dual roles at different cancer stages may explain the positive association between ABCG2 and worse prognosis of patients, though we suppose that ABCG2 may play an antioxidative and protective role in CRC according to our present results. Thus, in a complicated tumour environment with oxidative stress, ABCG2 may have an important antioxidative role, but not be sufficient to control the development of cancer.

The results of the present study indicated that ABCG2 inhibited ROS generation. Since ABCG2 is an efflux pump located in the cellular membrane, one possible mechanism is that ABCG2 prevents exogenous ROS inducers from entering the cells, thereby leading to a reduction in cellular ROS production (10). A previous study indicated that in the brains of patients with Alzheimer's disease, overexpression of ABCG2 protected cells from ROS-mediated toxicity and inflammatory response (15). Furthermore, ABCG2 was reported to be a novel GSH transporter $(27,28)$. The present in vitro study revealed a decreased level of intracellular GSH and higher levels of oxidative damage markers in shABCG2 cells, which indicated an antioxidative role of $\mathrm{ABCG} 2$ in $\mathrm{CRC}$.

The inflammatory reaction is one of the ROS-induced cellular responses. Excessive and uncontrollable production of ROS for a longer period of time may result in persistent inflammation (7). It has been indicated that chronic inflammation is an important factor in carcinogenesis (29). In accordance with the results of other studies $(15,30)$, the present study indicated that ROS stimulated the expression of inflammatory genes in cells, including IL- 8 , MCP-1 and GRO- $\beta$. One important aspect in assessing the role of ABCG2 is to determine whether ABCG2 attenuates the ROS-induced inflammatory response. Notably, knockdown of ABCG2 significantly increased the ROS-stimulated expression of IL- 8 and GRO- $\beta$ at the mRNA protein levels. Furthermore, when ABCG2 was knocked down, the ROS-stimulated expression of IL- 8, MCP-1 and GRO- $\beta$ at the mRNA and/or protein level was significantly increased compared with that in control cells. Therefore, it was revealed that ABCG2 antagonized oxidative stress, which has an antiinflammatory effect.

The expression of NF- $\kappa \mathrm{B}$ target genes typically promotes cellular survival, having a critical role in cancer development. NF- $\kappa \mathrm{B}$ signaling controls the ability of pre-neoplastic as well as malignant cells to evade apoptosis-based tumor surveillance mechanisms (31). As observed in the present study, NF- $\kappa \mathrm{B}$ was overexpressed in $\mathrm{CRC}$ tissues, indicating its vital role in carcinogenesis. Furthermore, $N F-\kappa B$ is linked with diverse groups of extracellular signal inducers, including oxidants and inflammatory cytokines. The transcription of $\mathrm{NF}-\kappa \mathrm{B}$-dependent genes may also influence the level of ROS in cells (32). Numerous studies have demonstrated that the NF- $\kappa \mathrm{B}$ signaling pathway is activated by oxidative stress, which in turn leads to the upregulation of the expression of inflammatory genes, including IL- 8 and GRO- $\beta$, as NF- $\kappa \mathrm{B}$ binding sites are present in the promoter regions of these genes. $N F-\kappa B$ is of vital importance in regulating the expression of inflammatory genes. A previous study by our group also provided evidence that ABCG2 inhibited the $\mathrm{NF}-\kappa \mathrm{B}$ signaling pathway in cell models and in mouse brains, exerting a protective role against the ROS-induced inflammatory response (11). In the present study, $\mathrm{NF}-\kappa \mathrm{B}$ was activated in an oxidative stress environment in CRC cells, particularly when ABCG2 was downregulated. It was therefore indicated that $\mathrm{NF}-\kappa \mathrm{B}$ signaling participated in ABCG2-associated processes in CRC.

\section{Acknowledgements}

Not applicable.

\section{Funding}

The present study was supported by the Youth National Natural Science Foundation of China (grant nos. 81201908 and 81602147), the Youth Natural Science Foundation of Jiangsu Province (grant no. BK20160110), the Outstanding Youth Project of Nanjing City (grant no. JQX16026) and the Nanjing Medical Science and Technique Development Foundation (grant nos. QRX17117 and QRX17037).

\section{Availability of data and materials}

All data generated or analyzed during this study are included in this published article.

\section{Authors' contributions}

$\mathrm{SN}, \mathrm{YH}$ and MS carried out the in vitro cell experiments, manuscript preparation and statistical analysis; XQ and HL collected the clinical specimens, wrote the IHC analysis section and revised the manuscript; $\mathrm{CP}$ and $\mathrm{BK}$ contributed to the conception and design of the study, made the interpretation of data for the study and provided critical review. XZ and SS conceived, designed, supervised, analyzed and interpreted the data and provided critical review. All authors read and approved the manuscript and agree to be accountable for all aspects of the research in ensuring that the accuracy or integrity of any part of the study are appropriately investigated and resolved.

\section{Ethics approval and consent to participate}

The present study was approved by the Ethics Committee of Nanjing Drum Tower Hospital, and the informed consent forms were obtained when the patients were accepted for the study by the hospital. 


\section{Patient consent for publication}

Not applicable.

\section{Competing interests}

The authors declare that they have no competing interests.

\section{References}

1. Torre LA, Bray F, Siegel RL, Ferlay J, Lortet-Tieulent J and Jemal A: Global cancer statistics, 2012. CA Cancer J Clin 65: 87-108, 2015

2. Stone WL, Krishnan K, Campbell SE and Palau VE: The role of antioxidants and pro-oxidants in colon cancer. World J Gastrointest Oncol 6: 55-66, 2014.

3. Sreevalsan $\mathrm{S}$ and Safe S: Reactive oxygen species and colorectal cancer. Curr Colorectal Cancer Rep 9: 350-357, 2013.

4. Saud SM, Li W, Morris NL, Matter MS, Colburn NH, Kim YS and Young MR: Resveratrol prevents tumorigenesis in mouse model of Kras activated sporadic colorectal cancer by suppressing oncogenic Kras expression. Carcinogenesis 35: 2778-2786, 2014

5. Bond CE, Liu C, Kawamata F, McKeone DM, Fernando W Jamieson S, Pearson SA, Kane A, Woods SL, Lannagan TRM, et al: Oncogenic BRAF mutation induces DNA methylation changes in a murine model for human serrated colorectal neoplasia. Epigenetics 13: 40-48, 2018.

6. Myers JN, Schäffer MW, Korolkova OY, Williams AD, Gangula PR and M'Koma AE: Implications of the colonic deposition of free hemoglobin- $\alpha$ chain: A previously unknown tissue by-product in inflammatory bowel disease. Inflamm Bowel Dis 20: $1530-1547,2014$

7. Federico A, Morgillo F, Tuccillo C, Ciardiello F and Loguercio C: Chronic inflammation and oxidative stress in human carcinogenesis. Int J Cancer 121: 2381-2386, 2007.

8. Barrett CW, Ning W, Chen X, Smith JJ, Washington MK, Hill KE, Coburn LA, Peek RM, Chaturvedi R, Wilson KT, et al: Tumor suppressor function of the plasma glutathione peroxidase gpx3 in colitis-associated carcinoma. Cancer Res 73: 1245-1255, 2013.

9. Maliepaard M, Scheffer GL, Faneyte IF, van Gastelen MA, Pijnenborg AC, Schinkel AH, van De Vijver MJ, Scheper RJ and Schellens JH: Subcellular localization and distribution of the breast cancer resistance protein transporter in normal human tissues. Cancer Res 61: 3458-3464, 2001.

10. Pavek P, Merino G, Wagenaar E, Bolscher E, Novotna M, Jonker JW and Schinkel AH: Human breast cancer resistance protein: Interactions with steroid drugs, hormones, the dietary carcinogen 2-amino-1-methyl-6-phenylimidazo(4,5-b)pyridine, and transport of cimetidine. J Pharmacol Exp Ther 312: 144-152, 2005.

11. Shen $S$ and Zhang W: ABC transporters and drug efflux at the blood-brain barrier. Rev Neurosci 21: 29-53, 2010.

12. Westover D and Li F: New trends for overcoming ABCG2/ BCRP-mediated resistance to cancer therapies. J Exp Clin Cancer Res 34: 159, 2015.

13. Gupta N, Martin PM, Miyauchi S, Ananth S, Herdman AV, Martindale RG, Podolsky R and Ganapathy V: Down-regulation of BCRP/ABCG2 in colorectal and cervical cancer. Biochem Biophys Res Commun 343: 571-577, 2006.

14. Liu HG, Pan YF, You J, Wang OC, Huang KT and Zhang XH: Expression of ABCG2 and its significance in colorectal cancer. Asian Pac J Cancer Prev 11: 845-848, 2010.
15. Shen S, Callaghan D, Juzwik C, Xiong H, Huang P and Zhang W: ABCG2 reduces $\mathrm{ROS}-$ mediated toxicity and inflammation: A potential role in Alzheimer's disease. J Neurochem 114: 1590-1604, 2010.

16. Livak KJ, Wills QF, Tipping AJ, Datta K, Mittal R, Goldson AJ, Sexton DW and Holmes CC: Methods for qPCR gene expression profiling applied to 1440 lymphoblastoid single cells. Methods 59: 71-79, 2013.

17. Duan G, Tang Q, Yan H, Xie L, Wang Y, Zheng XE, Zhuge Y, Shen S, Zhang B, Zhang X, et al: A strategy to delay the development of cisplatin resistance by maintaining a certain amount of cisplatin-sensitive cells. Sci Rep 7: 432, 2017.

18. Li W, Chen H, Yu M and Fang J: Targeted delivery of doxorubicin using a colorectal cancer-specific ssDNA aptamer. Anat Rec (Hoboken) 297: 2280-2288, 2014.

19. Karin M: NF-kappaB and cancer: Mechanisms and targets. Mol Carcinog 45: 355-361, 2006.

20. Park MY, Kim MY, Seo YR, Kim JS and Sung MK: High-fat diet accelerates intestinal tumorigenesis through disrupting intestinal cell membrane integrity. J Cancer Prev 21: 95-103, 2016.

21. Perše M: Oxidative stress in the pathogenesis of colorectal cancer: Cause or consequence? BioMed Res Int 2013: 725710, 2013.

22. Obtułowicz T, Winczura A, Speina E, Swoboda M, Janik J, Janowska B, Cieśla JM, Kowalczyk P, Jawien A and Gackowski D: Aberrant repair of etheno-DNA adducts in leukocytes and colon tissue of colon cancer patients. Free Radic Biol Med 49: 1064-1071, 2010

23. Yuan Y, Yang Z, Miao X, Li D, Liu Z and Zou Q: The clinical significance of FRAT1 and ABCG2 expression in pancreatic ductal adenocarcinoma. Tumour Biol 36: 9961-9968, 2015.

24. Krishnamurthy P, Xie T and Schuetz JD: The role of transporters in cellular heme and porphyrin homeostasis. Pharmacol Ther 114: 345-358, 2007.

25. Ogino T, Kobuchi H, Munetomo K, Fujita H, Yamamoto M, Utsumi T, Inoue K, Shuin T, Sasaki J, Inoue M, et al: Serumdependent export of protoporphyrin IX by ATP-binding cassette transporter G2 in T24 cells. Mol Cell Biochem 358: 297-307, 2011.

26. Gnana-Prakasam JP, Reddy SK, Veeranan-Karmegam R, Smith SB, Martin PM and Ganapathy V: Polarized distribution of heme transporters in retinal pigment epithelium and their regulation in the iron-overload disease hemochromatosis. Invest Ophthalmol Vis Sci 52: 9279-9286, 2011.

27. Brechbuhl HM, Gould N, Kachadourian R, Riekhof WR, Voelker DR and Day BJ: Glutathione transport is a unique function of the ATP-binding cassette protein ABCG2. J Biol Chem 285: 16582-16587, 2010.

28. Krzyżanowski D, Bartosz G and Grzelak A: Collateral sensitivity: ABCG2-overexpressing cells are more vulnerable to oxidative stress. Free Radic Biol Med 76: 47-52, 2014.

29. Reuter S, Gupta SC, Chaturvedi MM and Aggarwal BB: Oxidative stress, inflammation, and cancer: How are they linked? Free Radic Biol Med 49: 1603-1616, 2010.

30. Satapati S, Kucejova B, Duarte JA, Fletcher JA, Reynolds L, Sunny NE, He T, Nair LA, Livingston KA, Fu X, et al: Mitochondrial metabolism mediates oxidative stress and inflammation in fatty liver. J Clin Invest 125: 4447-4462, 2015.

31. Karin M: Nuclear factor-kappaB in cancer development and progression. Nature 441: 431-436, 2006.

32. Morgan MJ and Liu ZG: Crosstalk of reactive oxygen species and NF- $\kappa$ B signaling. Cell Res 21: 103-115, 2011. 